\title{
Peertechz
}

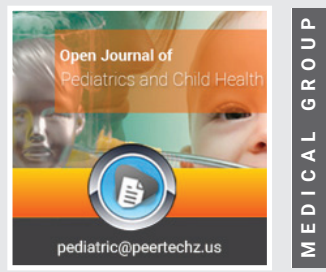

\section{Parental Alienation Syndrome} (PAS): Definition, humanistic profiles and clinical hypothesis

\section{of absorption with "adaptation disorder". Clinical evidences}

\author{
Giulio Perrotta* \\ Psychologist sp.ing in Strategic Psychotherapy, Forensic Criminologist, Legal Advisor sp.ed SSPL, \\ Researcher, Essayist, Institute for the study of psychotherapies - ISP, Via San Martino della Battaglia \\ no. 31,00185 , Rome, Italy
}

\begin{abstract}
Purpose: The present research aims to find clinical evidence for the starting hypothesis: parental alienation is a form of psychological violence that is part of the adjustment disorder fuelled by dysfunctional parental conduct.

Methods: Using the Perrotta Integrative Clinical Interview (PICl-1C, for children), a restricted and low sample of patients was selected (21 subjects), all aged between 4 and 10 years, with a clinically relevant behavioural manifestation (and a presumed "label" of parental alienation), with parents in the process of marital separation not yet concluded and in a conflictual or in any case difficult intra-familiar relational context. Anonymity was guaranteed to all.

Results: According to the PICl-1C, $100 \%(21 / 21)$ of cases fall into one of the six identified subtypes of adjustment disorder: a) $18,5 \%$ (4/21), disruptive mood dysregulation disorder (cat. 8); b) 13,7\% (3/21), maladaptive separation disorder (cat. 9); c) 23,4\% (5/21), oppositional defiant disorder (cat. 10); d) 23,4\% (5/21), explosiveintermittent disorder (cat. 11); e) 7,3\% (1/21), uninhibited social engagement disorder (cat. 12); f) 13,7\% (3/21), attachment disorder (cat. 13).

Conclusions: It can therefore be concluded, with all the limitations of the selected population sample, which is not representative, that the hypothesis of considering PAS (or PAD) as a variant of the general adaptation disorder, due to parental behaviour that feeds the dysfunctionality of the trauma suffered by the minor, can be substantially correct, also pointing out the correlation between the severity of the symptoms suffered (and the psychopathological condition found) and the prolonged exposure to stressful events.
\end{abstract}

\section{Introduction}

"Parental Alienation Syndrome" (PAS) is a controversial psychological dysfunctional dynamic that, according to the 1985 theories of US physician Richard Gardner, is activated on minor children involved in both parental separation and divorce (defined as "conflictual") and in contexts of alleged intrahousehold and family violence [1]. Gardner himself defines it as a disorder that normally arises in the context of child custody disputes, defined in three degrees, in ascending order of influence, each to be treated with a specific psychological and legal approach; it would therefore be the consequence of an alleged (voluntary or involuntary) 'reprogramming' of children by a pathological parent (so-called 'alienating'), a sort of brainwashing that would lead children to lose contact with the reality of affections and to display unjustified and continuous resentment and contempt towards the other parent (so-called 'alienated'), using disparaging expressions referring to the other parent, false accusations of neglect towards the child, violence or abuse (in the worst cases, even sexual abuse), the construction of a "virtual family reality" of terror and harassment that would generate, in the children, deep feelings 
of fear, distrust and hatred towards the "alienated" parent. The children would then ally themselves with the suffering parent, showing themselves to be infected by that suffering, beginning to support the vision of the 'alienating' parent. According to Gardner, such 'programming' would destroy the relationship between the children and the 'alienated' parent, as the former would refuse any contact, even by telephone, with the latter [2].

The following criteria should be checked for the presence of PAS [3-5]:

1) The child reports the abuse only if spurred on by the supporting parent

2) Existence of a contradiction between the child's accusation and the comfortable presence of the accused parent

3) A lively and quarrelsome participation of the parent who supports the complaint;

4) A tendency to manipulate on the part of the juvenile or a clear need to please. However, four other diagnostic criteria were later identified:

5) Transitional difficulties when the child separates from the alienating parent to spend visitation time with the alienated parent;

6) antagonistic or destructive behaviour during visits with the alienated parent;

7) Pathological or paranoid bonding with the alienating parent;

8) Strong and healthy bond with the alienated parent before the alienation process took place.

Gardner's theory, however, suggests basing the diagnosis of PAS also on the observation of eight presumed primary symptoms in the child [6-11]:

1) The denigration campaign, in which the child mimics and mimics the "alienating" parent's messages of contempt towards the "alienated" parent. In a normal situation each parent would not allow the child to show disrespect and slander the other. In PAS, however, the 'alienating' parent does not question such disrespect, but may even go so far as to encourage it;

2) The weak rationalisation of the rancour, whereby the child explains the reasons for his discomfort in the relationship with the alienated parent with illogical, senseless or even merely superficial reasons (examples cited, "He always raises his voice when he tells me to brush my teeth", or "He always tells me "Don't interrupt!");

3) the lack of ambivalence, whereby the rejected parent is described by the child as "completely negative" whereas the other is seen as "completely positive";
4) The phenomenon of the independent thinker indicates the child's determination to assert that he or she is a person who can reason without influence and that he or she has worked out the terms of the denigration campaign on his or her own without input from the "alienating" parent;

5) The automatic support to the "alienating" parent is a stance of the child always and only in favour of the "alienating" parent, whatever kind of conflict arises;

6) The absence of guilt, whereby all expressions of contempt towards the 'alienated' parent find justification in the fact that they are deserved, a sort of 'just punishment';

7) The borrowed scenarios, i.e. statements that cannot reasonably come directly from the child, such as the use of phrases, words, expressions or the quotation of situations not normally inherent to a child of that age to describe the faults of the excluded parent

8) The extension of hostilities to the extended family of the rejected parent, involving, in the alienation, the family, friends and new emotional relationships (a partner or companion) of the rejected parent.

Gardner stated that, in his opinion, the uncontrolled instillation of PAS would be a true form of emotional violence, capable of producing significant trauma both in the present and in the future lives of the children involved $[6,8,10,12$ 15]. These consequences include severe psychopathological processes such as: altered reality examination; narcissism; weakening of the capacity to feel empathy; lack of respect for authority (even to the point of externalizing typically antisocial traits), extended also to non-parental figures; paranoia; psychopathologies linked to gender identity; and, finally, a lack of respect for authority [16-40, 51-57].

According to Gardner [41-44], PAS could present itself at the moment of diagnosis, like any other pathology, even with different levels of severity (mild, moderate, severe PAS), depending on the intensity and effectiveness of the programming. Moreover, the author hypothesised that, depending on the greater or lesser appropriateness of the chosen therapy, PAS could in fact evolve

a) In a resolving sense (disappearance of symptoms and complete remission);

b) In an ameliorative direction (with symptomatic relief and partial remission);

c) In a stabilising direction (with constant severity of symptoms);

d) In a worsening sense (worsening of the pathology, up to the state of "living death").

The parenting aspects of separations could be clearly defined, if one could fully understand the concept that, in the family, there are two 'couple entities', distinct in their mutual rights, duties and responsibilities: the 'marital couple' and 
the 'parental couple'. A 'marital conflict', therefore, does not necessarily (or must) also trigger a 'parental conflict', and any conflicts between the two entities could be addressed with the help of family mediation. In part, the rules governing the 'separation' event may contribute to the problem. In order to govern the world of affection, one sometimes relies on a 'global system of antagonisms', on mechanisms of judicial conflict, on a 'procedural truth' with a winning party and a losing party. The institution of single-parent custody, so widely used in the past, is an element that reinforces the perspective in terms of "winner and loser". In the judicial context and, more generally, within the "global system of antagonisms", children often assume the role of "defenceless civilians" in a war of domination: real losers of an ideological vision that identifies a spouse/parent/children nucleus in the role of the victim, and the losing spouse/parent in the role of the violent and cruel executioner. A detachment from the reality of parental affection, which - according to theories - could trigger the Parental Alienation Syndrome when a parent comes to perceive the children as non-persons: as a means, that is, to acquire more power in the conflict, or as a tool to give vent and satisfaction to feelings of anger and discomfort typical of the 'married couple'. It is the passage to the act, the overcoming of the perception and the loss of the boundaries of the self, the direct use of the children as a "relational weapon" in the conflict of the "married couple", one of the factors that can lead to the onset of PAS $[8,10]$.

Gardner's theories and research results on the subject of parental alienation syndrome have, however, been the subject of criticism both from a legal and a strictly clinical point of view, due to their alleged lack of scientific validity and reliability, despite the fact that in 2010-2011 the European Court of Human Rights in Strasbourg ruled in favour [2]. For these reasons, the hypothesis of a redefinition into "Parental Alienation Disorder" (PAD), as proposed by Bernet (one of the main proponents of the inclusion of PAS in the fifth edition of the DSM), has been debated for years $[45,46]$. What emerges clearly is the very scarce number of scientific works supporting the research on the validity and reliability of Gardner's theory, including the will of the working group of the fifth revision of the DSM [47] not to include PAS in the Diagnostic and Statistical Manual of Mental Disorders because of its unscientific nature.

\section{Working hypothese and methodologies}

If we try to analyse PAS and its possible redefinition as PAD from a technical point of view, a number of elements emerge which, in the writer's opinion, merit attention:

1) The hypotheses in which PAS would apply would not include the hypotheses of actual abuse, violence and neglect. This is because PAS is a perpetrated and continuous condition of psychological violence, from which future psychopathologies would spring. Even if one were to admit the psychological nature of PAS, one would still have to consider, for the purposes of its objective existence and effective manifestation, variability factors that could condition its origin and course. Reference should be made to aspects such as age, gender, the degree of communication and cognition reached by the child, as well as the possibility that the alienating parent accepts to take charge in order to reestablish a functional communication between the child and his/her spouse, in order to neutralise the effects of the previous harmful behaviour towards the alienated person.

2) The symptomatology described in subjects affected by PAS falls perfectly within other nosographies already contained in the $D S M-V$. In particular we are talking about "adjustment disorder", which occurs when an individual has significant difficulty in adapting to or coping with a significant psychosocial stressor. The maladaptive response usually involves otherwise normal emotional and behavioural reactions that occur more intensely than usual (taking into account contextual and cultural factors), causing severe distress, preoccupation with the stressor and its consequences, and functional impairment. Common features include mild depressive symptoms, anxiety symptoms and traumatic stress symptoms or a combination of the three. According to the DSM-5, there are six distinct types, which are characterised by the following predominant symptoms: depressed mood, anxiety, depression mixed with anxiety, conduct disorder, mixed emotion and conduct disorder, and 'unspecified'. Unlike major depression, the disorder is caused by an external stressor and generally resolves once the individual is able to adapt to the situation. The condition is different from anxiety disorder, which lacks the presence of a stressor, or from post-traumatic stress disorder and acute stress disorder, which are usually associated with a more intense stressor. People exposed to repeated trauma are at greater risk, even if that trauma is in the distant past. Age may be a factor because young children have fewer coping resources; children are also less likely to assess the consequences of a potential stressor. A stressor is generally an event of a severe and unusual nature that an individual or group of individuals experiences. Stressors that cause adjustment disorders may be severely traumatic or relatively minor, such as the loss of a partner, a poor report card or moving to a new neighbourhood. It is thought that the more chronic or recurrent the stressor is, the more likely it is to produce a disorder. The objective nature of the stressor is of secondary importance. The most crucial link of stressors with their pathogenic potential is their perception by the patient as stressful. The presence of a causal stressor is essential before a diagnosis of adjustment disorder can be made. There are some stressors that are more common in different age groups; in adulthood these are marital conflict, financial conflict, health problems for oneself, one's partner or dependent children, personal tragedies such as death or personal loss and job loss or unstable working conditions, e.g. takeover or dismissal of a company; in childhood and adolescence these are family conflict or separation of parents, school problems or changing schools, sexuality problems, death, illness or trauma in the family. In time this condition may evolve into other more structured and marked disorders $[10,48]$. In any case, a targeted psychotherapeutic intervention is necessary $[49,50]$.

Without calling into question new nosographic structures and diagnostic modifications, the writer suggests excluding the hypothesis of including PAS (or PAD) in the psychodiagnostic manual and speaking instead of a form of adaptation disorder. 


\section{Results}

Trying to support this hypothesis, the writer administered the PICI-1 (version C) [58-62] to a restricted and nonrepresentative sample of patients (21 subjects, 8 males and 13 females), all aged between 4 and 10 years, with a clinically relevant behavioural manifestation (and a presumed "label" of parental alienation), with parents undergoing a marital separation that had not yet been concluded and in a conflictual or in any case difficult intra-familiar relational context, in the absence of a well-defined psychopathological picture or diagnosed by the public neuropsychiatric service.

The selected setting, taking into account the protracted pandemic period (already in progress since the beginning of the present research), is the online platform via Skype and Videocall Whatsapp, both for the clinical interview and for the administration. The present research work was carried out from July 2019 to June 2021. All participants were guaranteed anonymity and being a sample population under the age of 18 , specific authorization has been requested from parents or guardians, in accordance with the law. This research has no financial backer and does not present any conflicts of interest. The dictates of the Helsinki Convention of 1964 have been respected.

Before presenting the result of the administration of the PICI-1 (version C), it is necessary to specify that in the clinical interview used, "adjustment disorder" was actually broken down to better adapt to the clinical reality. In the theoretical model of the PICI-1, for the part of the children's disorders, one does not find the category "adjustment disorder" because this latter is the macrocategory of six other disorders:

a) 18,5\% (4/21). Disruptive Mood Dysregulation Disorder (cat. 8), as a habitual, persistent and pervasive pattern, with onset between five and ten years of age, characterised by systematic and persistent irritability involving outbursts of anger, aggression and frequent mood swings: severe explosions of anger; current explosions of anger, at least three episodes per week; violent physical and/or verbal reactions; physical and/or verbal reactions disproportionate in both duration and intensity; reactions of anger and/or violence incompatible with age; irritable mood for a good part of the day; negative feelings directed towards the family, friend and/or school environment; low tolerance of anxiety and/or frustration; intolerance of any form of education contrary to the child's wishes and/or expectations.

b) $13,7 \%$ (3/21). Maladaptive Separation Disorder (cat. 9), as a habitual, persistent and pervasive pattern, with onset between the ages of two and four years, characterised by systematic and persistent difficulty in letting go of parents or caregivers, constant and excessive fear that something tragic will happen to them and systematic refusal to leave home or remain alone in the home: difficulty in letting go of parents or own caregiver; explosions of anger; violent physical and/or verbal reactions; physical and/or verbal reactions disproportionate in both duration and intensity; constant and/ or excessive fear that something tragic will happen to them or their caregiver; Easily irritable, anxious and/or depressed mood (with notes of apathy, restlessness and strong melancholy) in the presence of a separating circumstance; negative feelings directed towards the separating event; low tolerance of anxiety and/or frustration; systematic refusal to leave home and/or remain alone in the home.

c) $23,4 \%$ (5/21). Oppositional Defiant Disorder (cat. 10), as a habitual, persistent and pervasive pattern, with onset between five and ten years of age, characterised by systematic and persistent difficulty in regulating and controlling one's emotions and behaviour: choleric and/or easily irritable mood; explosions of anger; violent physical and/or verbal reactions; physical and/or verbal reactions disproportionate in both duration and intensity; oppositional behaviour; vengeful behaviour; negative feelings towards those in authority; low tolerance of anxiety and/or frustration; traits of hyperactivity.

d) $23,4 \%$ (5/21). Explosive-Intermittent Disorder (cat 11), as a habitual, persistent and pervasive pattern, with onset between four and eight years of age, characterised by systematic and persistent difficulty in managing anger and rage: choleric and/or easily irritable mood; explosions of anger; violent physical and/or verbal reactions; physical and/or verbal reactions disproportionate in both duration and intensity; behaviour in reaction to events wrongly perceived as damaging to one's personal sphere; poor management of anger and/or rage, even in completely harmless events; negative feelings directed towards third parties; low tolerance of anxiety and/ or frustration; poor ability to resist aggressive and/or violent impulse.

e) $\quad 7,3 \%(1 / 21)$. Uninhibited Social Engagement Disorder (cat. 12), as a habitual, persistent and pervasive pattern, with onset between five and ten years of age, characterised by systematic and persistent displays of excessively physical and uninhibited behaviour towards others: unstable mood; uninhibited verbal behaviour with persons not belonging to the family nucleus; uninhibited physical behaviour with persons not belonging to the family nucleus; direct and excessively friendly approach with persons not belonging to the family nucleus; attentionseeking with persons not belonging to the family nucleus; constant need for physical contact with persons not belonging to the family nucleus; excessively trusting feelings directed towards third parties (not previously known); low tolerance to anxiety and/or frustration with respect to the search for contact and attention; absence of reticence or hesitation in leaving the safe place with unknown persons.

f) $13,7 \%$ (3/21). Attachment Disorder (cat. 13), as a habitual, persistent and pervasive pattern, with onset between two and five years of age, which refers to the disturbed and/or inadequate social relational mode that characterises the child in relation to his level of psychosocial development, either due to a distortion of the secure base, or to a total or partial absence of attachment. Two main clinical forms are known: INHIBITED TYPE (13a): difficulty in establishing interpersonal relationships; dysfunctional adaptation to common life circumstances; excessive inhibition; excessive hypervigilance; contradictory attitude towards caregivers; little social involvement; 
difficulty in affective regulation; low tolerance to anxiety and/ or frustration; unexplainable fear and/or outbursts of anger. DISINHIBITED TYPE (13b): easiness to engage in interpersonal relationships; independent and overly functional adaptation to the circumstances of common life; excessive disinhibition; excessive hypovigilance; excessive search for detachment and separation from caregivers; excessive social involvement and/ or excessive sociability; affective overregulation; low tolerance to anxiety and/or frustration with respect to loneliness; lack of shyness towards the stranger with whom he has contact.

All these six disorders, in children, are the consequence of trauma or repeated dysfunctional behaviour that has prevented the child from adapting in a functional way to future circumstances.

On this theoretical basis, therefore, the administration of the PICI-1C clinical interview confirmed the initial hypothesis of the "adaptation disorder", in its six variants, in $100 \%$ of the cases, as shown in the table:

\begin{tabular}{|c|c|c|c|}
\hline No. & $\begin{array}{l}\text { Age / } \\
\text { gender }\end{array}$ & $\begin{array}{l}\text { Exposure } \\
\text { to } \\
\text { stressful } \\
\text { events }\end{array}$ & Symptoms suffered before pici-1c administration \\
\hline 1 & $4 / \mathrm{M}$ & 3 years & anger, aggression, impulsiveness \\
\hline 2 & $4 / \mathrm{M}$ & 4 years & $\begin{array}{l}\text { excessive need for attention, excessive need for care, } \\
\text { phobias }\end{array}$ \\
\hline 3 & $5 / \mathrm{M}$ & 4 years & $\begin{array}{l}\text { excessive need for attention, excessive need for care, } \\
\text { obsessive thoughts, difficult to deal with frustration }\end{array}$ \\
\hline 4 & $5 / \mathrm{M}$ & 4 years & $\begin{array}{l}\text { excessive need for attention, excessive need for care, } \\
\text { obsessive thoughts }\end{array}$ \\
\hline 5 & $5 / \mathrm{M}$ & 2 years & $\begin{array}{l}\text { anger, aggression, impulsiveness, excessive need for } \\
\text { attention }\end{array}$ \\
\hline 6 & $6 / \mathrm{M}$ & 1 year & anger, aggression, impulsiveness \\
\hline 7 & $6 / \mathrm{M}$ & 3 years & $\begin{array}{l}\text { excessive need for attention, excessive need for care, } \\
\text { obsessive thoughts }\end{array}$ \\
\hline 8 & $6 / \mathrm{M}$ & 2 years & $\begin{array}{l}\text { anger, aggression, impulsiveness, excessive need for } \\
\text { attention }\end{array}$ \\
\hline 9 & $6 / F$ & 2 years & $\begin{array}{l}\text { anger, aggression, impulsiveness, excessive need for } \\
\text { attention }\end{array}$ \\
\hline 10 & $7 / F$ & 4 years & $\begin{array}{l}\text { excessive need for attention, excessive need for care, } \\
\text { obsessive thoughts }\end{array}$ \\
\hline 11 & 7/F & 3 years & $\begin{array}{l}\text { anger, aggression, impulsiveness, excessive need for } \\
\text { attention }\end{array}$ \\
\hline 12 & $7 / F$ & 2 years & $\begin{array}{l}\text { anger, aggression, impulsiveness, excessive need for } \\
\text { attention }\end{array}$ \\
\hline 13 & $8 / F$ & 6 years & $\begin{array}{l}\text { excessive need for attention, excessive need for care, } \\
\text { obsessive thoughts, difficult handling of frustration }\end{array}$ \\
\hline 14 & $9 / \mathrm{F}$ & 2 years & $\begin{array}{l}\text { excessive need for attention, excessive need for care, } \\
\text { obsessive thoughts }\end{array}$ \\
\hline 15 & $9 / \mathrm{F}$ & 5 years & $\begin{array}{l}\text { anger, aggression, impulsiveness, excessive need for } \\
\text { attention }\end{array}$ \\
\hline 16 & $9 / F$ & 6 years & $\begin{array}{l}\text { difficult management of frustration, } \\
\text { transgression of social and cohabitation rules, } \\
\text { anti-social and anti-authority behaviour }\end{array}$ \\
\hline 17 & $9 / \mathrm{F}$ & 1 year & anger, aggression, impulsiveness \\
\hline 18 & $9 / \mathrm{F}$ & 4 years & excessive need for care, phobias, panic \\
\hline 19 & $10 / F$ & 5 years & $\begin{array}{l}\text { difficult management of frustration, } \\
\text { transgression of social and cohabitation rules, } \\
\text { anti-social and anti-authority behaviour }\end{array}$ \\
\hline 20 & $10 / F$ & 6 years & $\begin{array}{l}\text { anger, aggression, impulsiveness, } \\
\text { panic attacks, obsessive thoughts }\end{array}$ \\
\hline
\end{tabular}

obsessive thoughts, aggression,

21 10/F 8 years impulsiveness, difficult handling of frustration transgression of social rules and rules of coexistence anti-social and anti-authority behaviour

The limits of this research are:

1) The use of a population sample that is not sufficiently representative, although the result of $100 \%$ suggests a good reliability of the psychodiagnostic instrument if applied to a larger sample of the population.

2) PICI-1 consists of two clinical interviews, based on the age of the interviewed subject; however, the one referring to the child and pre-adolescent age cannot be used in relation to MMPI-II because the theoretical assumption, the reference model and the nosography used are different.

3) PICI-1 is not yet standardised psychometric instrument but are proposed, despite the excellent results obtained and already published in international scientific journals [58-62].

\section{Working hypothese and methodologies}

It can therefore be concluded, with all the limitations of the selected population sample, which is not representative, that the hypothesis of considering PAS (or PAD) a variant of the general adaptation disorder, due to parental behaviour that feeds the dysfunctionality of the trauma suffered by the minor, can be substantially correct, also pointing out the correlation between the severity of the symptoms suffered (and the psychopathological condition found) and the prolonged exposure to stressful events.

\section{References}

1. Vaccaro S, Barea C (2011) PAS. Presunta Sindrome di Alienazione Genitoriale, Edit press, Firenze.

2. Pingitore M (2019) Nodi e snodi nell'alienazione parentale. Nuovi strumenti psicoforensi per la tutela dei diritti dei figli, Milano, Franco Angeli Ed.

3. Gardner RA (1985) Recent Trends in Divorce and Custody Litigation. Academy Forum. Bloomfield, The American Academy of Psychoanalysis and Dynamic Psychiatry 29. Link: https://bit.ly/3hyaX9L

4. Gardner RA (1998) Recommendations for Dealing with Parents who Induce a Parental Alienation Syndrome in their Children. Journal of Divorce \& Remarriage 28. Link: https://bit.ly/3hz4Fa7

5. Gardner RA (2001) Should Courts Order PAS Children to Visit/Reside with the Alienated Parent? A Follow-up Study. The American Journal of Forensic Psychology 19. Link: https://bit.ly/3q08snS

6. Camerini GB, Pingitore M, Lopez G (2016) Alienazione parentale. Innovazion cliniche e giuridiche, Milano, Franco Angeli Ed. Link: https://bit.ly/3dLoQk1

7. Fornari U (2015) Trattato di psichiatria forense, Utet Giuridica

8. Perrotta G (2019) Psicologia generale, Luxco Ed., 1st ed.

9. Perrotta G (2019) Psicologia dinamica, Luxco Ed., 1st ed.

10. Perrotta G (2019) Psicologia clinica, Luxco Ed., 1st ed.

11. Perrotta G (2019) The reality plan and the subjective construction of one's

Citation: Perrotta G (2021) Parental Alienation Syndrome (PAS): Definition, humanistic profiles and clinical hypothesis of absorption with "adaptation disorder". Clinical evidences. Open J Pediatr Child Health 6(1): 036-042. DOI: https://dx.doi.org/10.17352/ojpch.000035 
perception: the strategic theoretical model among sensations, perceptions, defence mechanisms, needs, personal constructs, beliefs system, social influences and systematic errors. J Clinical Research and Reports 1. Link: https://bit.ly/3b34baH

12. Perrotta G (2020) Psychological trauma: definition, clinical contexts, neural correlations and therapeutic approaches. Curr Res Psychiatry Brain Disord CRPBD-100006. Link: https://bit.ly/37UD3bz

13. Perrotta G (2020) Human mechanisms of psychological defence: definition, historical and psychodynamic contexts, classifications and clinical profiles. Int J Neurorehabilitation Eng 7: 1. Link: https://bit.ly/2L0I5dJ

14. Perrotta G (2020) Dysfunctional attachment and psychopathological outcomes in childhood and adulthood. Open J Trauma 4: 012-021. Link: https://bit.ly/3bhnXPg

15. Perrotta G (2020) Neonatal and infantile abuse in a family setting. Open $J$ Pediatr Child Health 5: 034-042. Link: https://bit.ly/37Ty2je

16. Perrotta G (2019) Attention Deficit Hyperactivity Disorder: definition, contexts, neural correlates and clinical strategies. J Addi Adol Beh 2. Link: https://bit.ly/3hyNCVE

17. Perrotta G (2019) Specific learning and language disorders: definitions, differences, clinical contexts and therapeutic approaches. J Addi Adol Beh 2. Link: https://bit.ly/3hh68Tx

18. Perrotta G (2019) Tic disorder: definition, clinical contexts, differential diagnosis, neural correlates and therapeutic approaches. J Neurosci Rehab 1-6. Link: https://bit.ly/3rEagQm

19. Perrotta G (2019) Anxiety disorders: definitions, contexts, neural correlates and strategic therapy. J Neur Neurosci 6: 046. Link: https://bit.ly/2WSmiaT

20. Perrotta G (2019) Neural correlates in eating disorders: Definition, contexts and clinical strategies. J Pub Health Catalog 2: 137-148. Link: https://bit.ly/3mWmf8s

21. Perrotta G (2019) Post-traumatic stress disorder: Definition, contexts, neural correlations and cognitive-behavioral therapy. J Pub Health Catalog 2: 40-47. Link: https://bit.ly/3rvaCc6

22. Perrotta G (2019) Sleep-wake disorders: Definition, contexts and neural correlations. J Neurol Psychol 7: 09. Link: https://bit.ly/3hoBiGO

23. Perrotta G (2019) Depressive disorders: Definitions, contexts, differential diagnosis, neural correlates and clinical strategies. Arch Depress Anxiety 5 : 009-033. Link: https://bit.ly/2KADvDm

24. Perrotta G (2019) Panic disorder: definitions, contexts, neural correlates and clinical strategies. Current Trends in Clinical \& Medical Sciences 1. Link: https://bit.ly/38IG6D5

25. Perrotta G (2019) Obsessive-Compulsive Disorder: definition, contexts, neural correlates and clinical strategies. Cientific Journal of Neurology 1: 08-16. Link: https://bit.ly/3pxNbNu

26. Perrotta G (2019) Behavioral addiction disorder: definition, classifications, clinical contexts, neural correlates and clinical strategies. J Addi Adol Beh 2 Link: https://bit.ly/3rAT9ip

27. Perrotta G (2019) Delusions, paranoia and hallucinations: definitions, differences, clinical contexts and therapeutic approaches. Cientific Journal of Neurology (CJNE) 1: 22-28.

28. Perrotta G (2019) Paraphilic disorder: definition, contexts and clinical strategies. J Neuro Research 1: 4. Link: https://bit.ly/3gxr1t3

29. Perrotta G (2019) Internet gaming disorder in young people and adolescent: a narrative review. J Addi Adol Beh 2. Link: https://bit.ly/3rTbAyZ

30. Perrotta G (2019) Bipolar disorder: definition, differential diagnosis, clinical contexts and therapeutic approaches. J Neuroscience and Neurological Surgery 5. Link: https://bit.ly/34SoC67

31. Perrotta G (2020) Suicidal risk: definition, contexts, differential diagnosis, neural correlates and clinical strategies. J Neuroscience Neurological Surgery 6: 114. Link: https://bit.ly/3aMqcu5

32. Perrotta G (2020) Pathological gambling in adolescents and adults: definition, clinical contexts, differential diagnosis, neural correlates and therapeutic approaches. ES J Neurol 1: 1004. Link: https://bit.ly/34RmUlj

33. Perrotta G (2020) Pedophilia: definition, classifications, criminological and neurobiological profiles and clinical treatments. A complete review. Open $\mathrm{J}$ Pediatr Child Health 5: 019-026. Link: https://bit.ly/38Jzggz

34. Perrotta G (2020) The concept of altered perception in "body dysmorphic disorder": the subtle border between the abuse of selfies in social networks and cosmetic surgery, between socially accepted dysfunctionality and the pathological condition. J Neurol Neurol Sci Disord 6: 001-007. Link: https://bit.ly/3wffHXp

35. Perrotta G (2020) Sexual orientations: a critical review of psychological clinical and neurobiological profiles. Clinical hypothesis of homosexual and bisexual positions. Int J Sex Reprod Health Care 3: 027-041. Link: https://bit.ly/38DtEVa

36. Perrotta G (2020) Cuckolding and Troilism: definitions, relational and clinica contexts, emotional and sexual aspects and neurobiological profiles. A complete review and investigation into the borderline forms of the relationship: Open Couples, Polygamy, Polyamory. Annals of Psychiatry and Treatment Ann Psychiatry Treatm 4: 037-042. Link: https://bit.ly/2TFODD3

37. Perrotta G (2020) Borderline Personality Disorder: definition, differential diagnosis, clinical contexts and therapeutic approaches. Ann Psychiatry Treatm 4: 043-056. Link: https://bit.ly/3hx2B1N

38. Perrotta G (2020) Narcissism and psychopathological profiles: definitions, clinical contexts, neurobiological aspects and clinical treatments. J Clin Cases Rep 4: 12-25. Link: https://bit.ly/2X8wzzF

39. Perrotta G (2020) Dysfunctional sexual behaviors: definition, clinical contexts neurobiological profiles and treatments. Int J Sex Reprod Health Care 3: 061 069. Link: https://bit.ly/3hxT4aU

40. Perrotta G (2020) Bisexuality: Definition, humanistic profiles, neural correlates and clinical hypotheses. J Neuroscience and Neurological Surgery 6. Link: https://bit.ly/2LpzwJx

41. Brown AL (2008) Criminal Rewards : The Impact of Parent Alienation Syndrome on Families. Affilia 23: 388-396. Link: https://bit.ly/3htjuuw

42. Faller KC (1998) The Parental Alienation Syndrome: What is it and What Data Support it?. Child Maltreatment American Professional Society on the Abuse of Children. Link: https://bit.ly/3AoQiOh

43. Bruch CS (2001) Parental Alienation Syndrome and Parental Alienation: Getting It Wrong in Child Custody Cases. Family Law Quarterly 35. Link: https://bit.ly/3hyZEOz

44. Wood CL (2012) The Parental Alienation Syndrome: A Dangerous Aura of Reliability. Loyola of Los Angeles Law Review 29.

45. Bernet W (2008) Parental Alienation Disorder and DSM-V. American Journal of Family Therapy 36: 349-366. Link: https://bit.ly/2TEG0sx

46. Bernet W (2017) Understanding the reality of parental alienation. Elsevie Science Direct 43: 507-509. Link: https://bit.ly/2SPNp88

47. APA (2013) DSM-V, Washington.

48. Maercker A, Lorenz L (2018) Adjustment disorder diagnosis: Improving clinica utility. World J Biol Psychiatry 19: S3-S13. Link: https://bit.ly/3e1Wlif

Citation: Perrotta G (2021) Parental Alienation Syndrome (PAS): Definition, humanistic profiles and clinical hypothesis of absorption with "adaptation disorder". Clinical evidences. Open J Pediatr Child Health 6(1): 036-042. DOI: https://dx.doi.org/10.17352/ojpch.000035 
49. Perrotta G (2020) The strategic clinical model in psychotherapy: theoretical and practical profiles. J Addi Adol Behav 3: 5. Link: https://bit.ly/3aPMx9X

50. Perrotta G (2020) Accepting "change" in psychotherapy: from consciousness to awareness. Journal of Addiction Research and Adolescent Behaviour 3.

51. Perrotta G (2020) Affective Dependence: from pathological affectivity to personality disorders. Definitions, clinical contexts, neurobiological profiles and clinical treatments. Health Sci 1: 1-7. Link: https://bit.ly/2TXmTdj

52. Perrotta G (2020) Psychotic spectrum disorders: definitions, classifications, neural correlates and clinical profiles. Ann Psychiatry Treatm 4: 070-084. Link: https://bit.ly/2TeoESI

53. Perrotta G (2021) Maladaptive stress: Theoretical, neurobiological and clinical profiles. Arch Depress Anxiety 7: 001-007. Link: https://bit.ly/3xihqw5

54. Perrotta G (2021) Etiological factors and comorbidities associated with the "Gender Dysphoria": Definition, clinical contexts, differential diagnosis and clinical treatments. Int J Sex Reprod Health Care 4: 001-005. Link: https://bit.ly/3xjddbK

55. Perrotta G (2021) The state of consciousness: from perceptual alterations to dissociative forms. Defining, neurobiological and clinical profiles. J Neuro Neurol Sci Disord 7: 006-018. Link: https://bit.ly/2TyN2yY

56. Perrotta G, Fabiano G (2021) Behavioural disorders in children and adolescents: Definition, clinical contexts, neurobiological profiles and clinical treatments. Open J Pediatr Child Health 6: 005-015. Link: https://bit.ly/3Ary6U7

57. Perrotta G (2021) Avoidant personality disorder: Definition, clinical and neurobiological profiles, differential diagnosis and therapeutic framework. $J$ Neuro Neurol Sci Disord 7: 001-005. Link: https://bit.ly/3p5S9SP

58. Perrotta G (2020) Perrotta Integrative Clinical Interview.

59. Perrotta G (2020) The structural and functional concepts of personality: The new Integrative Psychodynamic Model (IPM), the new Psychodiagnostic Investigation Model (PIM) and the two clinical interviews for the analysis of personality disorders (Perrotta Integrative Clinical Interview or PICl) for adults and teenagers (1TA version) and children (1C version), Psychiatry Peertechz, E-book. Link: https://bit.ly/2SqQevV

60. Perrotta G (2020) First revision of the Psychodiagnostic Investigation Mode (PIM-1R) and elaboration proposal of a clinical interview for the analysis of personality disorders (Perrotta Integrative Clinical Interview or $\mathrm{PICl}$ 1) for adults, teenagers and children. Psychiatry Peertechz, E-book. Link: https://bit.ly/2MQe3dY

61. Perrotta G (2020) "Perrotta Integrative Clinical Interview (PICl-1)" Psychodiagnostic evidence and clinical profiles in relation to the MMPI-II, Ann Psychiatry Treatm 4: 062-069. Link: https://bit.ly/3rqbgqX

62. Perrotta G (2021) "Perrotta Integrative Clinical Interview" (PICI) for adults and teenagers (1TA version) and children (1C version): new theoretical models and practical integrations between the clinical and psychodynamic approach Ann Psychiatry Treatm 5: 001-014. Link: https://bit.ly/3546iGM

63. Perrotta G (2021) Perrotta Integrative Clinical Interview (PICl-1): a new revision proposal for PICl-1TA. Two single cases. Glob J Medical Clin Case Rep 8: 041 049. Link: https://bit.ly/2UsevSY

\section{Discover a bigger Impact and Visibility of your article publication with}

\section{Peertechz Publications}

\author{
Highlights \\ * Signatory publisher of ORCID \\ * Signatory Publisher of DORA (San Francisco Declaration on Research Assessment) \\ * Articles archived in worlds' renowned service providers such as Portico, CNKI, AGRIS, \\ TDNet, Base (Bielefeld University Library), CrossRef, Scilit, J-Gate etc. \\ * Journals indexed in ICMJE, SHERPA/ROMEO, Google Scholar etc. \\ * OAI-PMH (Open Archives Initiative Protocol for Metadata Harvesting) \\ * Dedicated Editorial Board for every journa \\ * Accurate and rapid peer-review process \\ * Increased citations of published articles through promotions \\ * Reduced timeline for article publication \\ Submit your articles and experience a new surge in publication services \\ (https://www.peertechz.com/submission).
}

Peertechz journals wishes everlasting success in your every endeavours.

Copyright: @ 2021 Perrotta G. This is an open-access article distributed under the terms of the Creative Commons Attribution License, which permits unrestricted use distribution, and reproduction in any medium, provided the original author and source are credited.

Citation: Perrotta G (2021) Parental Alienation Syndrome (PAS): Definition, humanistic profiles and clinical hypothesis of absorption with "adaptation disorder". Clinical evidences. Open J Pediatr Child Health 6(1): 036-042. DOI: https://dx.doi.org/10.17352/ojpch.000035 